\title{
Metformin alleviates endometrial hyperplasia through the UCA1/miR-144/TGF-ß1/AKT signaling pathway
}

\author{
MIAO GUO ${ }^{1}$, JING-JING ZHOU ${ }^{2}$ and WEI HUANG ${ }^{3}$ \\ ${ }^{1}$ Department of Pathology, Xing Yuan (4th) Hospital of Yulin, Yulin, Shaanxi 719000; \\ ${ }^{2}$ Department of Gynecology, Ankang Hospital of Traditional Chinese Medicine, Ankang, Shaanxi 725000; \\ ${ }^{3}$ Department of Gynecology, Baoji Maternal and Child Health Hospital, Baoji, Shaanxi 721000, P.R. China
}

Received March 5, 2019; Accepted August 12, 2019

DOI: $10.3892 /$ ijmm.2019.4438

\begin{abstract}
The objective of the present study was to investigate the molecular mechanism underlying the role of metformin (Met) in reducing the risk of endometrial hyperplasia (EH). Reverse transcription-quantitative polymerase chain reaction, western blot and immunohistochemistry (IHC) assays were used to study the effects of Met and tamoxifen on the expression levels of urothelial cancer associated 1 (UCA1), microRNA-144 (miR-144) and other factors along the transforming growth factor- $\beta 1$ (TGF- $\beta 1) /$ protein kinase B (AKT) signaling pathway. In addition, MTT and flow cytometry assays were performed to detect the effect of Met on cell proliferation and apoptosis. Tamoxifen treatment increased the weight of the uterus and the level of UCA1, while decreasing the expression of miR-144. In addition, treatment with tamoxifen $(2.0$ and $3.5 \mu \mathrm{g})$ upregulated the protein expression levels of TGF- $\beta$ and p-AKT, while downregulating the protein expression of active Caspase- 3 in a dose-dependent manner. By contrast, Met reduced cell viability, promoted cell apoptosis, and reduced the expression levels of UCA1, TGF- $\beta$ and p-AKT, while upregulating the expression of miR-144 and active Caspase- 3 in a dose-dependent manner. Furthermore, Met also reduced the weight of uterus. However, tamoxifen and Met did not exert any effect on the protein levels of total AKT and total Caspase-3. The levels of TGF- $\beta$ and p-AKT proteins in the EH group were much higher when compared with those in the sham group, while Met treatment reduced these protein levels to a certain extent. In addition, the expression of active Caspase-3 in the EH group was much lower than that in the sham group, while Met treatment increased its level to a certain extent. In conclusion, the current study suggested that Met reduces the risk of $\mathrm{EH}$ by reducing the expression
\end{abstract}

Correspondence to: Dr Wei Huang, Department of Gynecology, Baoji Maternal and Child Health Hospital, 2 Xinjian Road East, Baoji, Shaanxi 721000, P.R. China

E-mail: endomoldye@yeah.net

Key words: endometrial hyperplasia, cell proliferation, microRNA-144, transforming growth factor- $\beta 1$, protein kinase B levels of UCA1, TGF- $\beta$ and p-AKT, while increasing the levels of miR-144 and active Caspase-3 in a dose-dependent manner.

\section{Introduction}

As a non-invasive and pre-cancerous growth of the endometrium, endometrial hyperplasia $(\mathrm{EH})$ is featured by an increased amount of endometrial tissues, exhibiting an increased endometrial gland to stroma ratio of over 1:1 and a modified glandular architecture (1). At present, approximately 200,000 new cases of EH are diagnosed annually in developed countries (2). The majority of EH cases are caused by long-term exposure to elevated levels of estrogen (3). In fact, the production of excessive estrogen by fat cells has been demonstrated to increase the risk of endometrial cancer (EC) and $\mathrm{EH}$ in obese patients (4).

As a primary contributor to fibrosis in the kidney, colon and lung, transforming growth factor- $\beta 1$ (TGF- $\beta 1$ ) can bind to type I and type II ALK5 receptors located on the plasma membrane, subsequently triggering the phosphorylation of $\operatorname{Smad} 2 / 3$, which in turn binds to Smad4 located in the nucleus, eventually activating the transcription and expression of TGF- $\beta 1(5,6)$. TGF- $\beta 1$ can also increase the risk of fibrosis by activating the non-Smad-dependent signaling pathways. $\beta$-catenin, integrin-linked kinase, protein kinase B (AKT), Ras homolog gene family member A and p38 mitogen-activated protein kinase have all been identified as downstream effectors of TGF- $\beta 1$ signaling in different types of cells, such as keratinocytes and mammary epithelial cells (7). In addition, TGF- $\beta 1$ signaling has been implicated in regulating the proliferation and hyperplasia of uterine epithelial cells (8).

As a type of RNA molecules without protein-coding functions, non-coding RNAs (ncRNAs) include several sub-classes, such as long non-coding RNAs (lncRNAs), microRNAs (miRNAs), small nuclear RNAs, small nucleolar RNAs, ribosomal RNAs and transfer RNAs. Among the different types of ncRNAs, IncRNAs refer to ncRNAs that contain at least 200 nucleotides (9). Growing evidence has indicated that lncRNAs are closely involved in the regulation of gene expression at the epigenetic, post-transcriptional and transcriptional levels (10). By contrast, miRNAs are short ncRNAs with a length of $<25$ nucleotides. Nevertheless, miRNAs can also regulate the expression of their target genes by binding to the 
3'-untranslated region of their target mRNAs (11). Extensive studies have revealed that miRNAs are involved in the regulation of numerous essential biological processes, whereas the abnormal expression of miRNAs was observed in a number of diseases, including cancer (12).

It has previously been reported that the deregulation of the TGF- $\beta 1$ signaling pathway was involved in the pathogenesis of EH (13). In addition, the IncRNA urothelial cancer associated 1 (UCA1) was demonstrated to deregulate the TGF- $\beta 1$ signaling pathway (13). Furthermore, miR-144-3p acts as a competing endogenous RNA for UCA1, while TGF- $\beta 1$ acts as a direct target gene of miR-144-3p (14). Notably, it has been reported that metformin (Met) modulated the expression of the IncRNA UCA1 (15); thus, it is hypothesized that Met may exert its therapeutic effect via targeting the UCA1/miR-144-3p/TGF- $\beta 1$ signaling pathway. In the present study, an EH mouse model was established by treating mice with increased concentrations of tamoxifen, and subsequently the effect of tamoxifen on the expression levels of UCA1, miR-144 and other factors along the TGF- $\beta 1 /$ AKT signaling pathway was investigated. Furthermore, the therapeutic role of Met in the treatment of EH was studied by measuring the effect of Met on the expression levels of UCA1, miR-144 and other factors along the TGF- $\beta 1 / A K T$ signaling pathway.

\section{Materials and methods}

Animals and treatments. In the present study, 60 female mice (8-weeks-old) weighing between 20 and $31 \mathrm{~g}$ were obtained from the Animal Center of Baoji Maternal and Child Health Hospital and kept in a specific-pathogen-free animal facility with a relative humidity of 50-60\% and a temperature of $20-25^{\circ} \mathrm{C}$. The light/dark cycle of the animal facility was set to $12 / 12 \mathrm{~h}$, and the mice had free access to water and food. After one week of adaptation, all mice were anesthetized using intraperitoneal injections of xylazine hydrochloride $(16-20 \mathrm{mg} / \mathrm{kg})$ and ketamine hydrochloride $(75-150 \mathrm{mg} / \mathrm{kg}$ ). Subsequently, the mid-lumbar dorsal region of each mouse was exposed for the surgical procedure. During the surgery, a square incision was created at the dorsal terminal of the ribcage through the muscle, thus exposing the fat pad region around the ovary. In the next step, the oviduct of the mouse was ligated and subsequently cauterized using heated forceps to prevent bleeding during the excision of the ovary. Following ovary excision, the remaining ovarian tissues were placed back into the peritoneal cavity prior to repeating the aforementioned procedure at the other side. Finally, the muscle openings were sealed with a 5-0 suture in conjunction with skin clips. Subsequent to the surgery, all mice were allowed to rest for 1 week prior to conducting subsequent experimental steps to ensure the successful establishment of a post-menopausal model.

Following the successful ovariectomy, the mice were divided into four groups (each, $n=15$ ), as follows: Sham group that included untreated control mice, and three tamoxifen-treated groups, in which mice received a daily dose of 1.0, 2.0 and $3.5 \mu \mathrm{g}$ tamoxifen for 7 consecutive days, respectively. For tamoxifen treatment, tamoxifen tablets (Yangtze River Pharmaceutical Co., Ltd.) were crushed into a thin powder, suspended in ethanol and then diluted using canola oil. The administration of tamoxifen in mice was performed orally using a gavage needle. In the sham group, the mice received only the same volume of canola oil instead of the tamoxifen suspension. Subsequent to the treatment with tamoxifen and the successful induction of EH (as determined via hematoxylin and eosin staining), the $3.5 \mu \mathrm{g}$ tamoxifen treated-mice were again divided into five groups (each, $n=3$ ) to receive Met treatment, as follows: Sham group, treated with phosphate-buffered saline (PBS); Met group, treated with a daily dose of $5 \mathrm{mg}$ Met (Tocris Bioscience); EH group, treated with a daily dose of $3.5 \mu \mathrm{g}$ tamoxifen; $\mathrm{EH}+$ Met group, treated with a daily dose of $5 \mathrm{mg}$ Met in conjunction with a daily dose of $3.5 \mu \mathrm{g}$ tamoxifen; and $\mathrm{EH}+\mathrm{AKT}$ inhibitor group, treated with the AKT inhibitor MK-2206 (Lifespan Biosciences, Inc.) dissolved in $30 \%$ Captisol at a dose of $120 \mathrm{mg} / \mathrm{kg}$ and administered by oral gavage in conjunction with a daily dose of $3.5 \mu \mathrm{g}$ tamoxifen. All treatments were administered once a day for 7 consecutive days. The successful establishment of the animal models was confirmed by hematoxylin and eosin (H\&E) staining among these groups. All experiments were performed according to the protocol approved by the Ethical Committee of Baoji Maternal and Child Health Hospital (Baoji, China).

Immunohistochemistry. Tissue samples were harvested, fixed in $4 \%$ paraformaldehyde for $48 \mathrm{~h}$, dehydrated, embedded in paraffin and sliced into $5 \mu \mathrm{m}$ sections. Gradient ethanol was used to dewax and hydrate the samples, followed by $2 \mathrm{~min}$ of antigen retrieval in $10 \mathrm{mM}$ citrate $(\mathrm{pH} 6.0)$ under a $720 \mathrm{~W}$ heating condition in a microwave. Subsequently, the sections were cooled-down at room temperature for $30 \mathrm{~min}$, blocked in 3\% hydrogen peroxide for $15 \mathrm{~min}$ and incubated at room temperature for $120 \mathrm{~min}$ with primary anti-TGF- $\beta 1$ (cat. no. ab92468, 1:5,000; Abcam) antibodies. Subsequent to sample washing with Tris-buffered saline/Tween-20, HRP-linked IgG secondary antibodies (cat no. ab6721, 1:1,500; Sigma-Aldrich; Merck KGaA) were used to treat the samples for $2 \mathrm{~h}$ at room temperature. A DAB substrate kit (Vector Laboratories, Burlingame, CA, USA) was then used to visualize the bound antibodies, while hematoxylin was used to stain the cell nuclei.

$R N A$ isolation and reverse transcription-quantitative polymerase chain reaction (RT- $q P C R)$. A miRNeasy Mini kit (Qiagen GmbH, Düsseldorf, Germany) was used to extract total RNA from endometrial tissue samples of each group after 7 days of treatment. A NanoDrop 1000 spectrophotometer (Thermo Fisher Scientific, Inc., Waltham, MA, USA) was used to assess the RNA purity and concentration. Next, a MiScript Reverse Transcription kit (Qiagen $\mathrm{GmbH}$ ) was used to synthesize the cDNA of UCA1, miR-144 and TGF- $\beta 1$ using the following reaction conditions: $37^{\circ} \mathrm{C}$ for $60 \mathrm{~min}$ and $95^{\circ} \mathrm{C}$ for 5 min. An ABI 7500 Real-Time PCR system (Applied Biosystems; Thermo Fisher Scientific, Inc.) and a miScript SYBR-Green PCR kit (Qiagen GmbH, Hilden, Germany) were then used to analyze the expression levels of UCA1, miR-144 and TGF- $\beta 1$ mRNA in a One-Step Real-Time PCR 96-well optical plate. The sequences of primers used in qPCR were the following: UCA1 forward, 5'-GCCCCTTGGACCATCACA-3', and reverse, 5'-GACGGCAGTTGGTGTGCTAT-3'; miR-144 forward, 5'-CGGTACAGTATAGATGATGTACT-3', and reverse, 5'-CAGTGCGTGTCGTGGAGT-3'; TGF- $\beta 1$ mRNA forward, 5'-AACTGCTTCCTGTATGGGGTC-3', and reverse, 
5'-AAGGCGTCGTCAATGGACTC-3'; U6 forward, 5'-CTC GCTTCGGCAGCACA-3', and reverse, 5'-AACGCTTCA CGAATTTGCGT-3'; GAPDH forward, 5'-CGGAGTCAA CGGATTTGGTCGTAT-3' and reverse, 5'-AGCCTTCTCCAT GGTGGTGAAGAC-3'. The reaction was performed using the following conditions: Initial activation at $95^{\circ} \mathrm{C}$ for $15 \mathrm{~min}$ and denaturation at $94^{\circ} \mathrm{C}$ for $15 \mathrm{sec}$, followed by annealing at $55^{\circ} \mathrm{C}$ for $30 \mathrm{sec}$ and a final extension at $72^{\circ} \mathrm{C}$ for $60 \mathrm{sec}$. U6 and GAPDH served as the internal control to normalize the expression levels of UCA1, miR-144 and TGF- $\beta 1$ mRNA, which were calculated using the $2^{-\Delta \Delta C q}$ method (16). Each reaction was repeated at least three times.

Cell culture and treatment. Two human endometrial cancer cell lines, AN3CA and Ishikawa, were obtained from the Cell Bank of the Chinese Academy of Sciences (Shanghai, China) and used to establish cell models in the current study. The two cell lines were cultured in a Dulbecco's modified Eagle's medium (Invitrogen; Thermo Fisher Scientific, Inc.) supplemented with $10 \%$ fetal bovine serum (Invitrogen; Thermo Fisher Scientific, Inc.), $100 \mathrm{mg} / \mathrm{ml}$ streptomycin sulfate and $100 \mathrm{U} / \mathrm{ml}$ penicillin. The cells were maintained in an incubator at $37^{\circ} \mathrm{C}$ and $5 \% \mathrm{CO}_{2}$. Subsequently, the cells were treated for $48 \mathrm{~h}$ with 10 and $20 \mu \mathrm{M}$ Met and compared with untreated cells, which served as the control group, to study the effect of Met on the expression of multiple target genes. Three independent experiments were performed.

Cell proliferation (MTT) assay. When AN3CA and Ishikawa cells reached $80 \%$ confluence, they were made into single cell suspensions. The cells were then seeded into a 96-well plate at a density of $6 \times 10^{3}$ cells/well in $0.2 \mathrm{ml}$ culture medium. Each well was treated with a 10\% MTT solution at 24, 48 and $72 \mathrm{~h}$ after cell culture. Following further culturing for $4 \mathrm{~h}$, the supernatant was discarded and $100 \mu \mathrm{l}$ dimethyl sulfoxide (Sigma-Aldrich; Merck KGaA, Darmstadt, Germany) was added into each well, followed by $10 \mathrm{~min}$ of incubation on a shaker to fully dissolve the formazan crystals produced by the living cells. The optical density (OD) value of each well was measured at $490 \mathrm{~nm}$ on a microplate reader. A cell viability curve was generated using time as the $\mathrm{x}$-axis and the $\mathrm{OD}$ value as the $y$-axis to evaluate the viability of AN3CA and Ishikawa cells subjected to different treatments.

Western blot analysis. To analyze the protein expression levels of TGF- $\beta 1$, total AKT and p-AKT in tissue and cell samples, the samples were treated with ice-cold lysis buffer (containing 1\% NP-40, 0.1\% sodium dodecyl sulfate, $50 \mathrm{mM}$ Tris-HCl, $\mathrm{pH} 7.4$, and $150 \mathrm{mM} \mathrm{NaCl}$ ) supplemented with protease inhibitors (Roche, Indianapolis, IN, USA). A bicinchoninic acid Protein Assay kit (Bio-Rad Laboratories, Inc.) was used to determine the concentration of protein according to the manufacturer's protocol. Next, $12 \%$ w/v sodium dodecyl sulfate-polyacrylamide gel electrophoresis was used to resolve the isolated protein, which was then electro transferred to a nitrocellulose membrane (Bio-Rad Laboratories, Inc., Hercules, CA, USA) for $2 \mathrm{~h}$ at $90 \mathrm{~V}$. PBS containing 5\% nonfat dry milk was then used to block the membrane for $60 \mathrm{~min}$ to eliminate non-specific binding. Subsequently, the membrane was incubated at $4^{\circ} \mathrm{C}$ overnight with polyclonal primary antibodies against TGF- $\beta 1$ (cat. no. ab92468, 1:5,000; Abcam), total AKT (cat. no. ab81283, 1:5,000; Abcam), p-AKT (cat. no. ab131443, 1:5,000; Abcam), total Caspase-3 (cat. no. ab13847, 1:5,000; Abcam), active Caspase-3 (cat no. ab2302, 1:5,000; Abcam) or $\beta$-actin (cat. no. ab8226, 1:5,000; Abcam) as the internal control. After the membrane was washed twice by PBS, it was further incubated at room temperature for $2 \mathrm{~h}$ with horseradish peroxidase (HRP)-conjugated secondary antibodies (cat. no. ab6721, 1:12,000; Abcam). An enhanced chemiluminescent kit (Pierce, Waltham, MA) was used to visualize antigen-antibody complexes, which were then analyzed by Quantity One software (Bio-Rad Laboratories, Inc.) to quantify the protein levels of TGF- $\beta 1$, total AKT, p-AKT, total Caspase- 3 and active Caspase-3. All experiments were run in triplicate.

Apoptosis analysis. Cells were harvested, washed twice with PBS and resuspended in $1 \mathrm{X}$ binding buffer to a final density of $4 \times 10^{5}$ cells per well. A total of $5 \mu \mathrm{l}$ PE Annexin V and $5 \mu 1$ 7-AAD were added to $100 \mu 1$ cell suspension. Samples were then incubated in darkness for $15 \mathrm{~min}$. The status of cell apoptosis was measured using an Annexin V-FITC apoptosis detection kit (Thermo Fisher Scientific, Inc.) and flow cytometry (BD Biosciences) following the manufacturer's protocols.

Statistical analysis. All data are presented as the mean \pm standard deviation, and SPSS software (version 11.5; SPSS, Inc., Chicago, IL, USA) was used to perform all statistical analyses. Analysis of variance with a Holms-Sidak post-hoc test was used to perform the statistical comparisons between different groups. A P-value of $<0.05$ was considered to denote a statistically significant difference.

\section{Results}

Differential expression of UCA1, miR-144 and TGF- $\beta 1$ among various groups. Different doses of tamoxifen (1.0, 2.0 and $3.5 \mu \mathrm{g}$ ) were used to establish an animal model of $\mathrm{EH}$, and the expression levels of UCA1, miR-144 and TGF- $\beta$ were then detected using RT-qPCR. As shown in Fig. 1, the uterine weight (Fig. 1A), as well as the expression levels of UCA1 (Fig. 1B), miR-144 (Fig. 1C) and TGF- $\beta$ (Fig. 1D), exhibited no significant differences between the sham and $1.0 \mu \mathrm{g}$ tamoxifen groups. However, when the concentration of tamoxifen was increased from 1 to $3.5 \mu \mathrm{g}$, the uterine weight (Fig. 1A) and the expression levels of UCA1 (Fig. 1B) and TGF- $\beta$ (Fig. 1D) were also markedly increased in a dose-dependent manner, while the expression of miR-144 was significantly decreased by the tamoxifen treatment.

Furthermore, western blot analysis was performed to compare the protein expression levels of TGF- $\beta$, total AKT, p-AKT, total Caspase- 3 and active Caspase- 3 among the four groups. As shown in Fig. 2, the protein levels of TGF- $\beta$ and p-AKT and in the sham group were comparable with those in the $1.0 \mu \mathrm{g}$ tamoxifen group. However, when the concentration of tamoxifen was increased from 1 to $3.5 \mu \mathrm{g}$, the protein levels of TGF- $\beta$ and p-AKT became significantly higher. By contrast, the protein levels of total AKT and total Caspase-3 were comparable among the sham and tamoxifen (1.0, 2.0 and $3.5 \mu \mathrm{g}$ ) groups. In addition, when the concentration of 


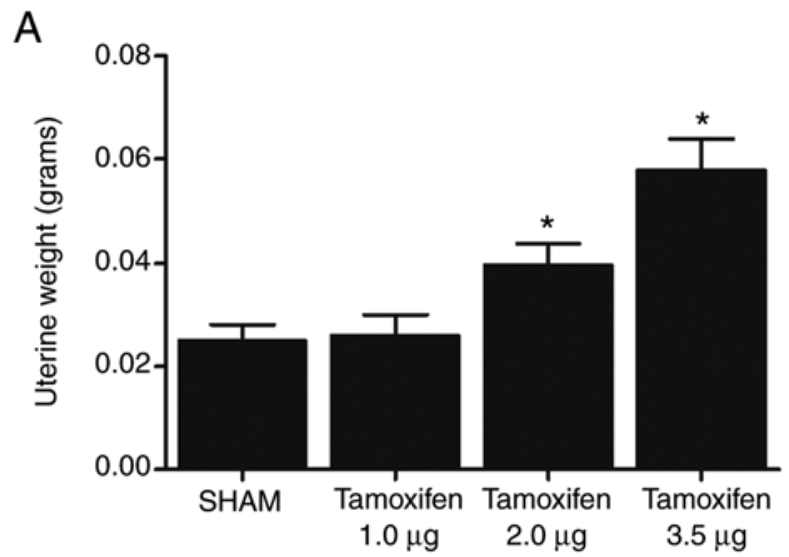

B
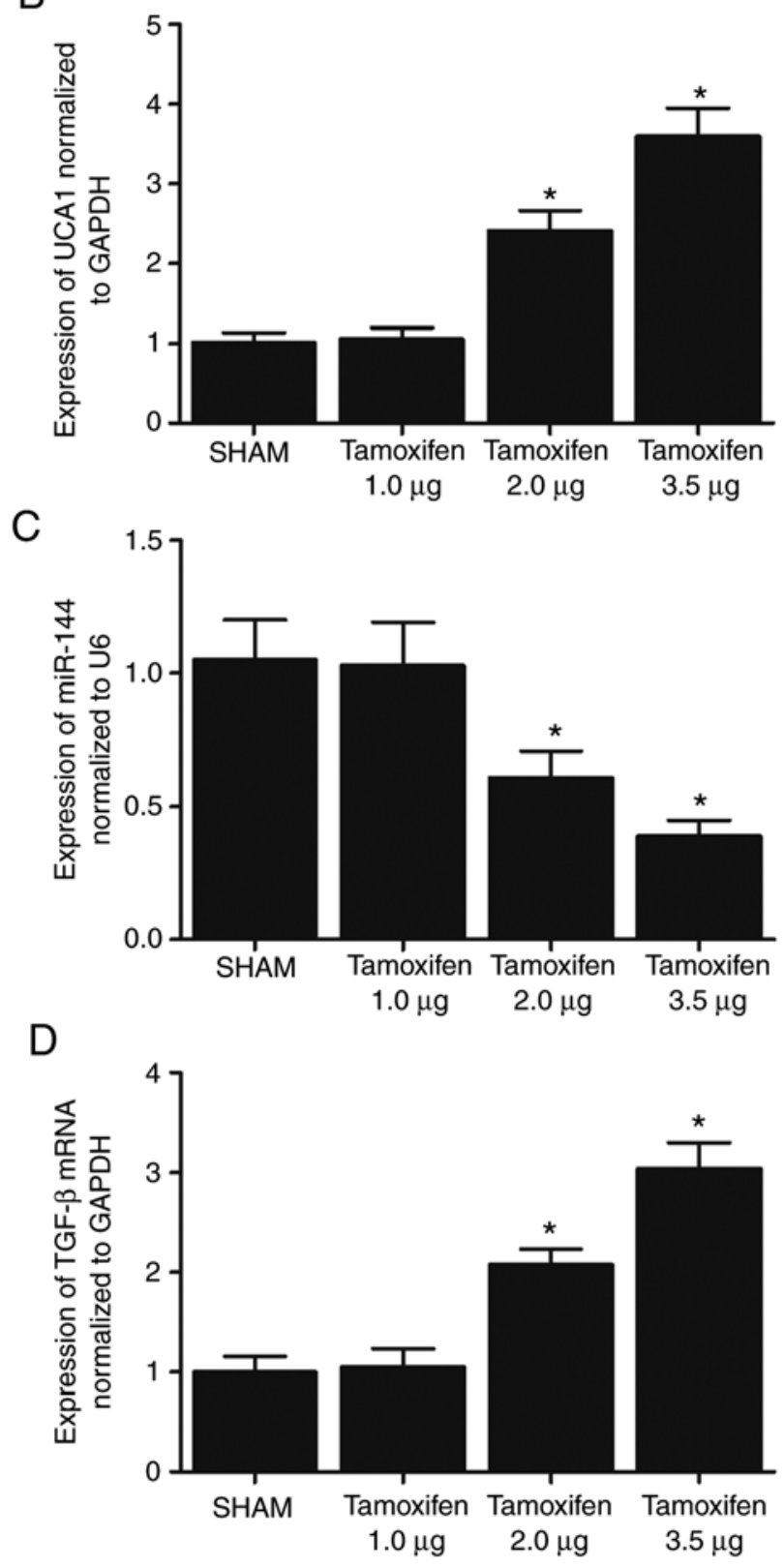

Figure 1. Differential expression levels of UCA1, miR-144 and TGF- $\beta$ in various treatment groups. Effect of tamoxifen on (A) uterine weight, and on (B) UCA1, (C) miR-144 and (D) TGF- $\beta$ expression levels. Tamoxifen (2.0 and $3.5 \mu \mathrm{g}$ ) increased the uterine weight and the mRNA levels of UCA1 and TGF- $\beta$ in a dose-dependent manner, while it dose-dependently decreased the level of miR-144. * $\mathrm{P}<0.05$ vs. sham group $(\mathrm{N}=3)$. UCA1, urothelial cancer associated 1 ; miR-144, microRNA-144; TGF- $\beta$, transforming growth factor- $\beta$. tamoxifen increased from 1 to $3.5 \mu \mathrm{g}$, the protein levels of active Caspase-3 were significantly decreased.

Met regulated the expression of key EH markers. Met was used to treat mice with $\mathrm{EH}$ induced by $3.5 \mu \mathrm{g}$ tamoxifen, and then the expression levels of UCA1, miR-144 and TGF- $\beta$ were compared among the sham, EH, Met, EH + Met and $\mathrm{EH}+\mathrm{AKT}$ inhibitor groups using RT-qPCR. The successful establishment of the animal model was validated via $H \& E$ staining, as shown in Fig. 3. As shown in Fig. 4, the administration of Met exerted no marked effect on the uterine weight (Fig. 4A), or on the expression levels of UCA1 (Fig. 4B), miR-144 (Fig. 4C) and TGF- $\beta$ (Fig. 4D) compared with those in the sham group. On the contrary, the uterine weight (Fig. 4A), and the expression levels of UCA1 (Fig. 4B) and TGF- $\beta$ (Fig. 4D) were significantly increased in the EH group, along with a significantly decreased level of miR-144 (Fig. 4C). Notably, the treatment with Met in EH mice partially restored the abnormal expression levels of UCA1, TGF- $\beta$ and miR-144, while treatment with AKT inhibitor in EH mice exerted similar effects.

Furthermore, western blot analysis was performed to compare the protein expression levels of TGF- $\beta$, total AKT, p-AKT, total Caspase-3 and active Caspase-3 and p-AKT among the sham, $\mathrm{EH}$, Met and $\mathrm{EH}+$ Met groups. As shown in Fig. 5, the protein levels of TGF- $\beta$ (Fig. 5A and B) and p-AKT (Fig. 5A and D) in the sham group were comparable with those in the Met group, while the EH group exhibited much higher levels of TGF- $\beta$ and p-AKT. However, the treatment of EH mice with Met partially restored the normal protein expression of TGF- $\beta$ and p-AKT. Furthermore, the protein levels of total AKT (Fig. 5A and C) and total Caspase-3 (Fig. 5A and E) were similar among the sham, EH, Met, EH + Met and $\mathrm{EH}+\mathrm{AKT}$ inhibitor groups. The protein levels of active Caspase-3 (Fig. 5A and F) were similar in the sham and Met groups, whereas treatment with $3.5 \mu \mathrm{g}$ tamoxifen significantly reduced the level of active Caspase- 3 (EH group). In addition, the inhibitory effect of tamoxifen on the expression of active Caspase-3 (Fig. 5F) was partially offset by the administration of Met or AKT inhibitor. IHC assays also produced similar results to those of the western blot analysis (Fig. 6).

Met affected cell survival and the in vitro expression of key EH markers. Various doses of Met (10 and $20 \mu \mathrm{M})$ were used to treat $\mathrm{AN} 3 \mathrm{CA}$ and Ishikawa cells, and subsequently the effect of Met on cell proliferation and apoptosis was detected by MTT and flow cytometry assays, respectively. Furthermore, RT-qPCR and western blot analysis were conducted to compare the levels of UCA1, miR-144, TGF- $\beta$, total AKT, p-AKT, total Caspase- 3 and active Caspase- 3 between the control and Met (10 and $20 \mu \mathrm{M})$ groups. As shown in Fig. 7, Met inhibited the proliferation (Fig. 7A) and promoted the apoptosis (Fig. 7B) of AN3CA cells in a dose-dependent manner. In addition, in AN3CA cells, treatment with Met reduced the expression of UCA1 mRNA (Fig. 7C), TGF- $\beta$ mRNA (Fig. 7E), TGF- $\beta$ protein (Fig. 7F and G) and p-AKT protein (Fig. 7F and I), while increasing the levels of miR-144 (Fig. 7D) and the expression of active Caspase-3 (Fig. 7F and K) in a dose-dependent manner. However, Met exerted no effect on the protein expression levels of total AKT (Fig. 7F and H) and total Caspase-3 
A

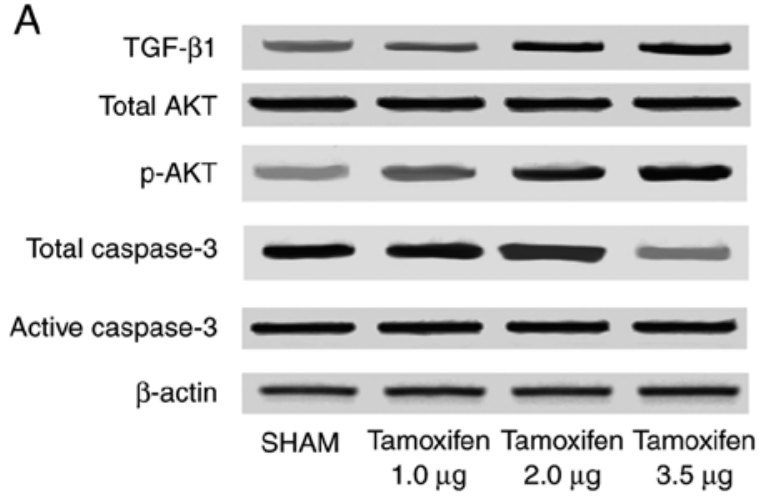

C

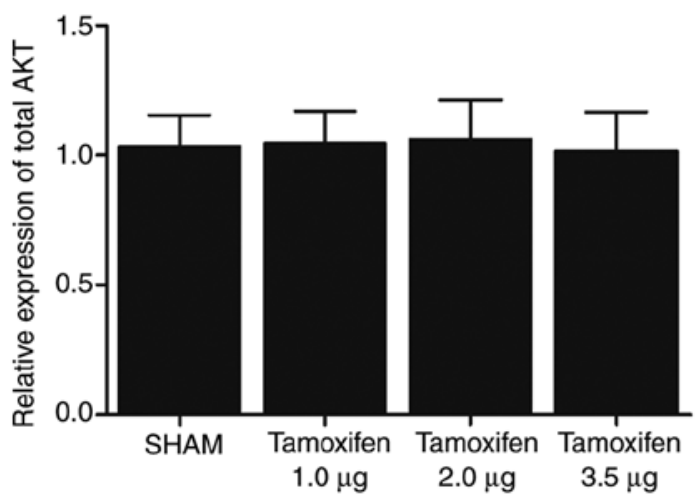

$\mathrm{E}$

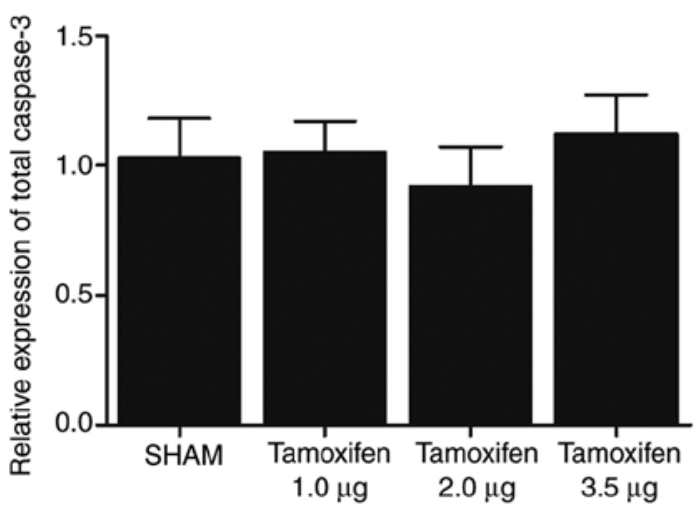

B

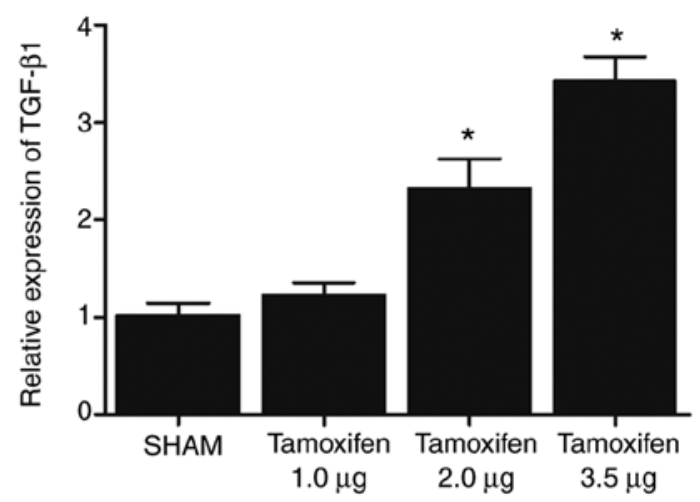

$\mathrm{D}$

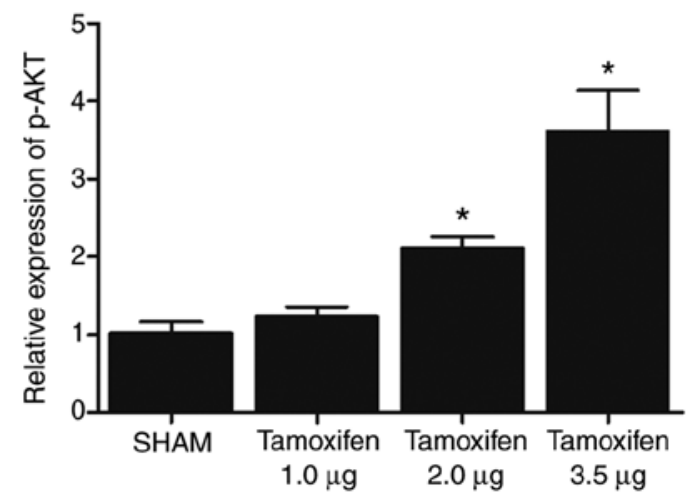

$\mathrm{F}$

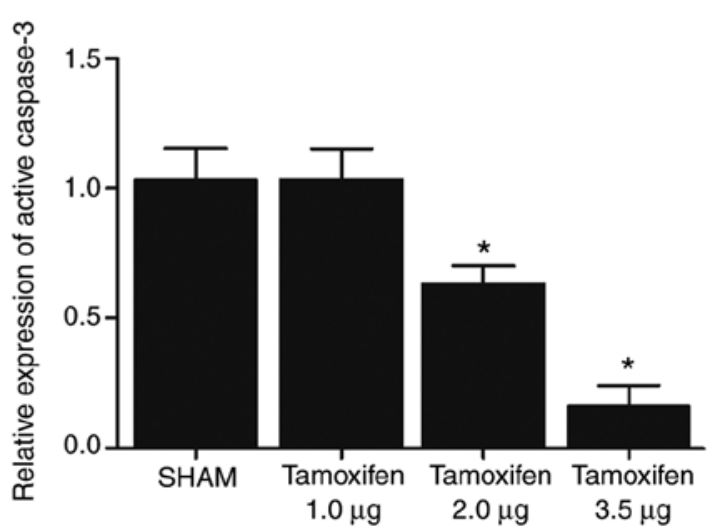

Figure 2. Expression levels of TGF- $\beta$, total AKT, p-AKT, total Caspase-3 and active Caspase- 3 in the various treatment groups. (A) Western blots of TGF- $\beta$, total AKT, p-AKT, total Caspase-3 and active Caspase-3 in mice treated with tamoxifen $(1.0,2.0$ and $3.5 \mu \mathrm{g})$. (B) TGF- $\beta 1$, (C) total AKT, (D) p-AKT, (E) total Caspase-3 and (F) active Caspase-3 expression levels are shown. Tamoxifen (2.0 and $3.5 \mu \mathrm{g}$ ) dose-dependently upregulated the protein expression levels of TGF- $\beta$ and p-AKT, while it dose-dependently downregulated the protein expression of active Caspase-3. Tamoxifen exerted no effect on the protein expression levels of total AKT and total Caspase-3. ${ }^{*} \mathrm{P}<0.05$ vs. sham group (N=3). UCA1, urothelial cancer associated 1; miR-144, microRNA-144; TGF- $\beta 1$, transforming growth factor- $\beta 1$.
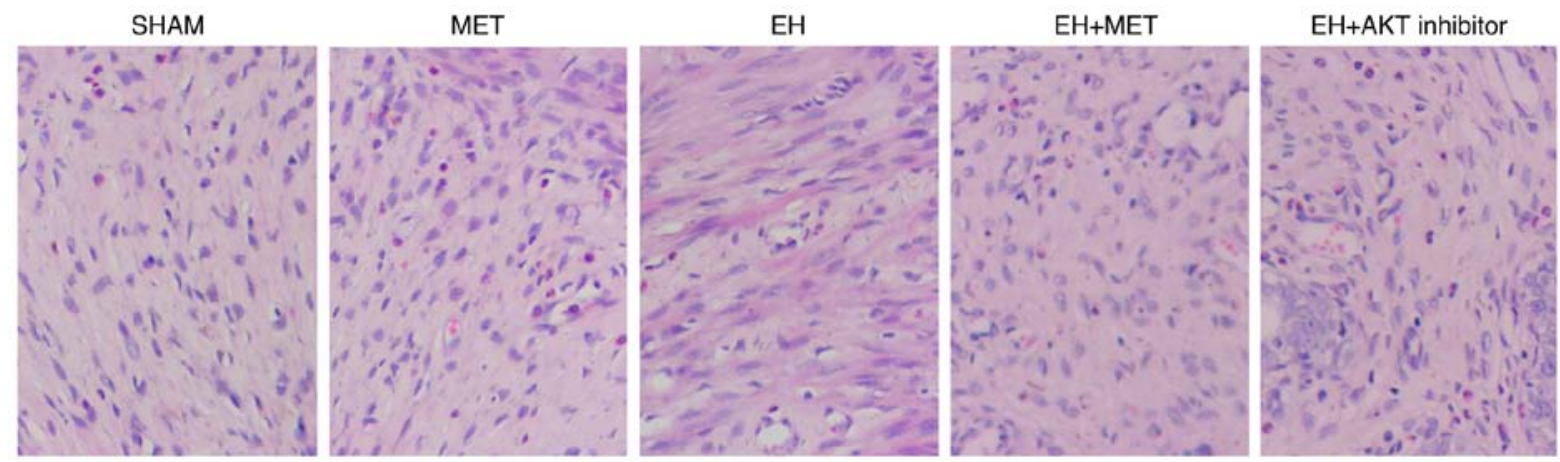

Figure 3. Hematoxylin and eosin staining confirmed the successful establishment of the animal model groups (magnification, x200). Met, metformin; $\mathrm{EH}$, endometrial hyperplasia; AKT, protein kinase B. 
A

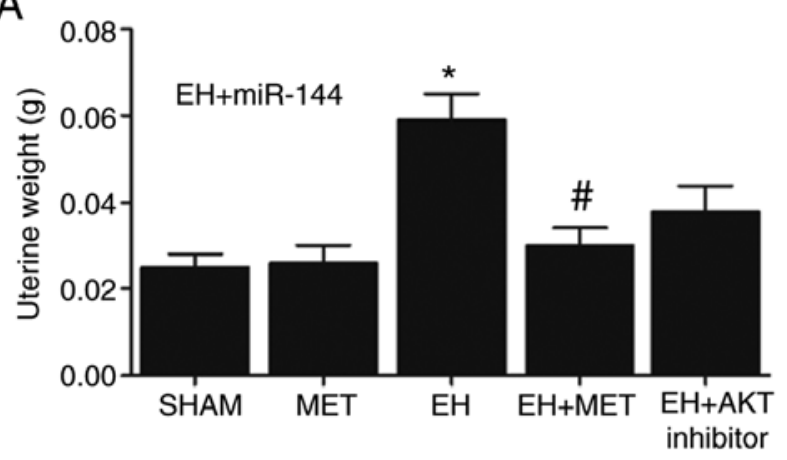

C

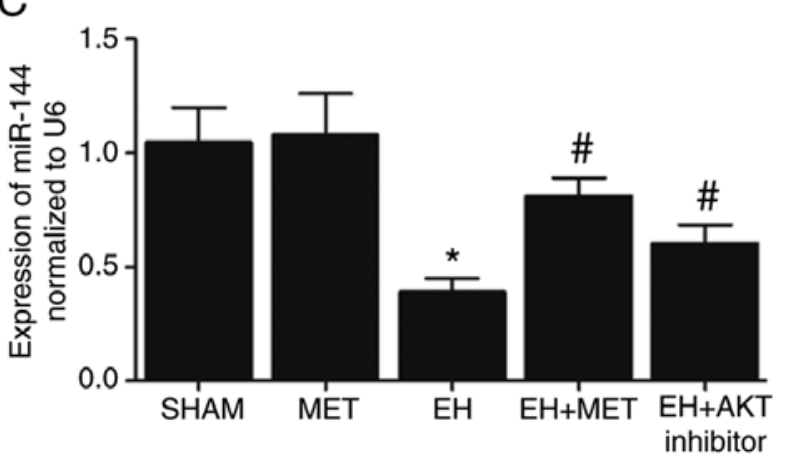

B
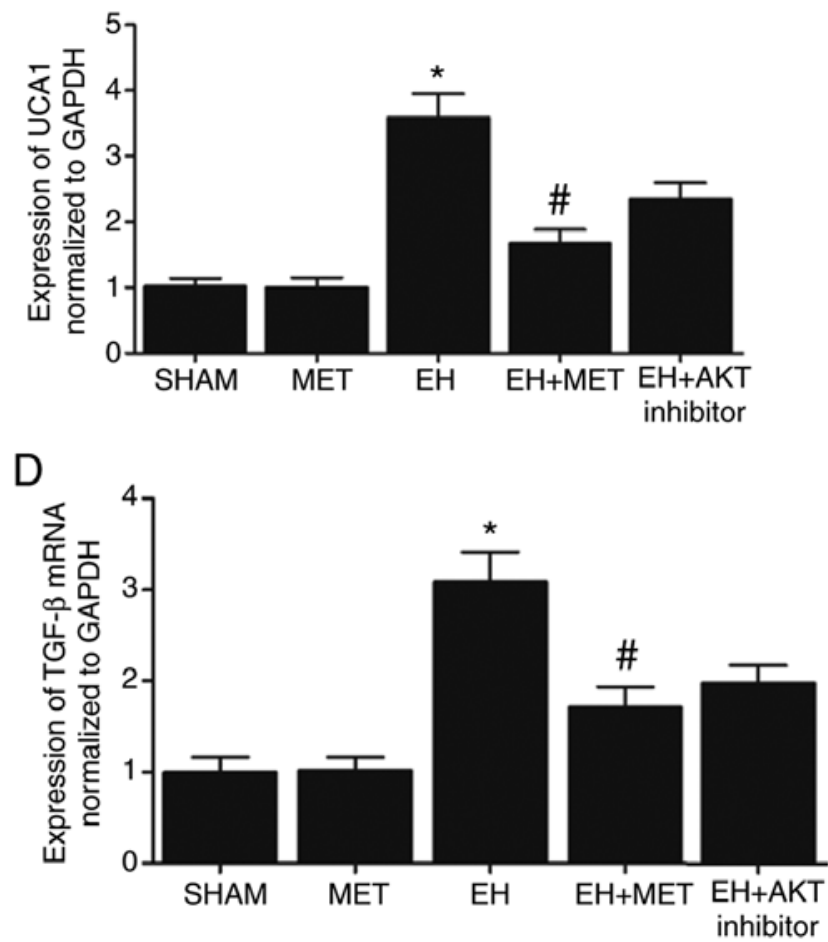

Figure 4. Differential expression levels of UCA1, miR-144 and TGF- $\beta$ following Met treatment. Effect of Met on (A) uterine weight, and on (B) UCA1, (C) miR-144 and (D) TGF- $\beta$ expression levels. Met partially restored the normal uterine weight that was increased by tamoxifen treatment, as well as Met partially restored the normal mRNA expression levels of UCA1, miR-144 and TGF- $\beta$ in the EH group. ${ }^{*} \mathrm{P}<0.05$ vs. sham group; ${ }^{\#} \mathrm{P}<0.05$ vs. EH group (N=3). Met, metformin; EH, endometrial hyperplasia; UCA1, urothelial cancer associated 1 ; miR-144, microRNA-144; TGF- $\beta$, transforming growth factor- $\beta$.

(Fig. 7F and 7J). Similar results were also obtained from Ishikawa cells (Fig. 8).

\section{Discussion}

$\mathrm{EH}$, considered as a precursor of EC, is caused by long-term exposure to estrogen and subsequent stimulation of endometrial growth. In fact, the presence of EH has been reported to increase the risk of EC (17). As a type of biguanide, Met (also known as N,N-dimethylbiguanide) is frequently used in the treatment of polycystic ovarian syndrome (PCOS) and type 2 diabetes mellitus, particularly in patients presenting insulin resistance or obesity (18-20). Given that EH is implicated in the development of insulin resistance, while Met has been found to exert an anti-metastatic, anti-invasive and anti-proliferative effect in several types of cancer, Met may also be used in EH treatment $(20,21)$. In vitro, Met has been demonstrated to induce the expression of PR in EC cells, thus enhancing the efficiency of progestin therapy and reducing the severity of progestin resistance that is often observed in long-term progestin treatment (22). In the present study, an animal of tamoxifen-induced $\mathrm{EH}$ was established and the $\mathrm{EH}$ mice were subsequently treated with Met. The results revealed that tamoxifen increased the uterine weight and the expression levels of UCA1, TGF- $\beta$ and p-AKT, while decreasing the expression levels of miR-144 and active Caspase-3. However, treatment with MT partially restored the normal expression of miR-144 and active Caspase-3.

A previous clinical trial revealed that the effect of Met is comparable with that of megestrol for the treatment of simple
EH (23). Another study demonstrated that Met may directly reverse impaired glycolysis and normalize mitochondrial function in PCOS patients with EH (24). Met was used to successfully treat several cases of atypical EH that was not responding to progestin treatment (25). In vitro studies also reported that Met was able to reduce the proliferation of prostate, ovarian, endometrial and breast cancer cells (26-29). A previous study on EC cell line also demonstrated a dose-dependent effect of Met treatment, while a meta-analysis confirmed that Met was able to reduce the incidence of pancreatic, hepatic, colorectal and breast cancer $(25,30)$. In a retrospective study of $\sim 1,000 \mathrm{EC}$ patients who were followed up for over 3 years, the patients treated with Met exhibited a longer overall survival in comparison with the patients not treated with Met (31). In another study on PCOS patients, an increasing dose of Met more significantly reduced the risk of EC (32). Since the risk of EC is increased by $>4$-fold in PCOS patients, the protective effect of Met against EC is significant in PCOS patients (30). In addition, since $>30 \%$ of PCOS patients eventually develop progestin resistance, novel treatments are required to overcome progestin resistance and to reduce the proliferation of endometrial cells (30).

It has been previously demonstrated that lncRNA UCA1 can bind to miR-144 expressed in A549 cells (14). In the current study, the effect of Met on cell proliferation and apoptosis, as well as on the expression levels of UCA1, miR-144, TGF- $\beta$, total AKT, p-AKT, total Caspase- 3 and active Caspase-3, was investigated in AN3CA and Ishikawa cells. The results demonstrated that Met reduced the cell viability and promoted cell apoptosis. In addition, Met 
A

$$
\text { TGF- } \beta 1
$$

Total AKT

p-AKT

Total caspase-3

Active caspase-3

$\beta$-actin

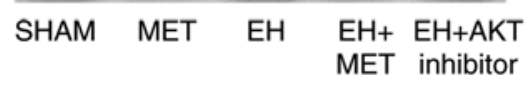

C

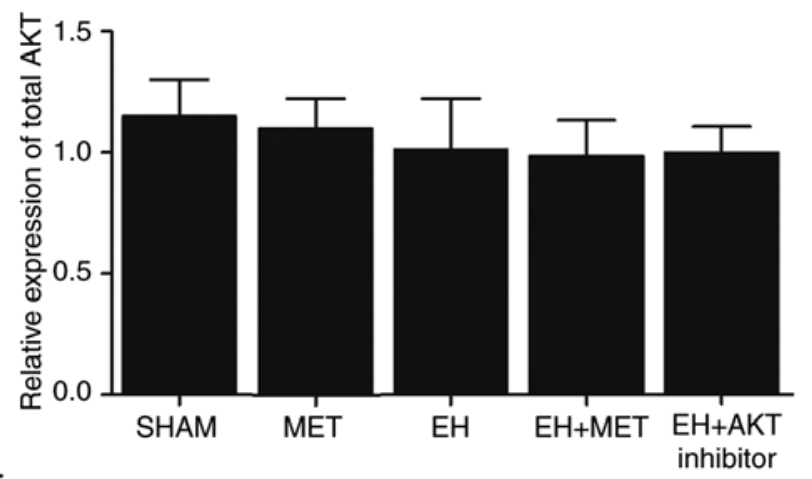

E

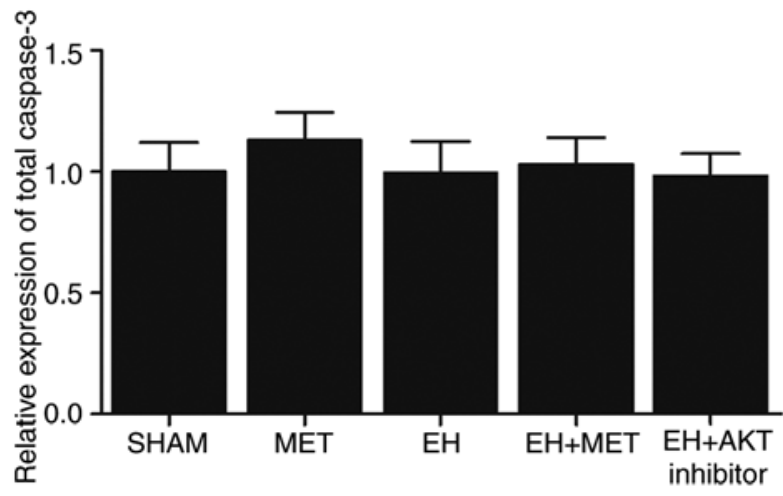

B

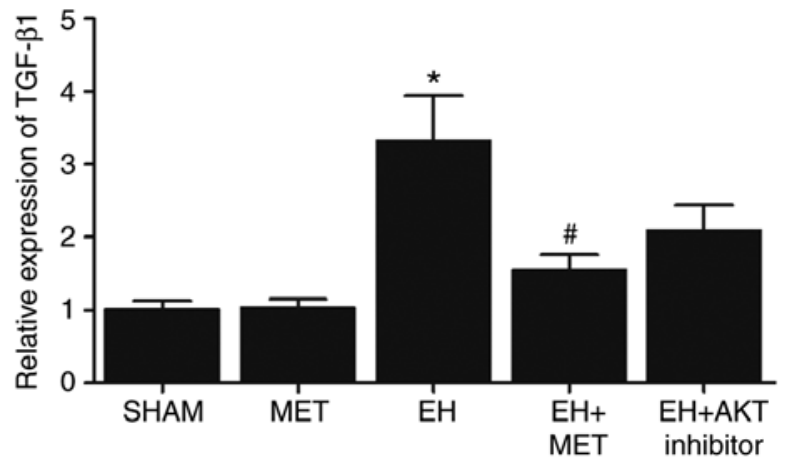

D

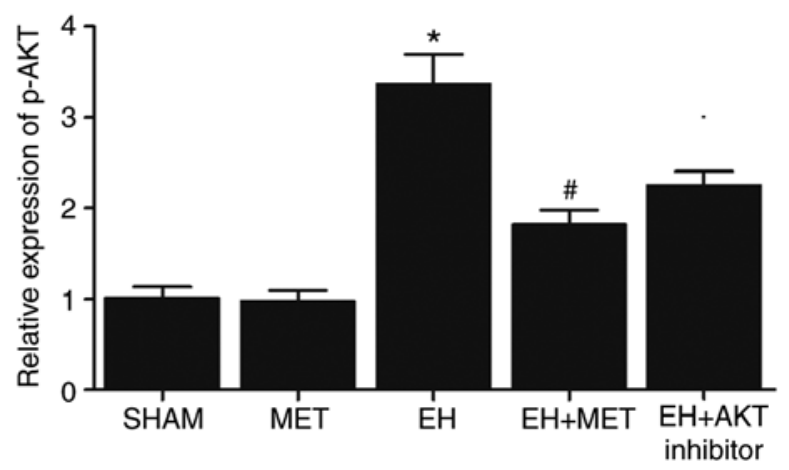

$F_{m}$

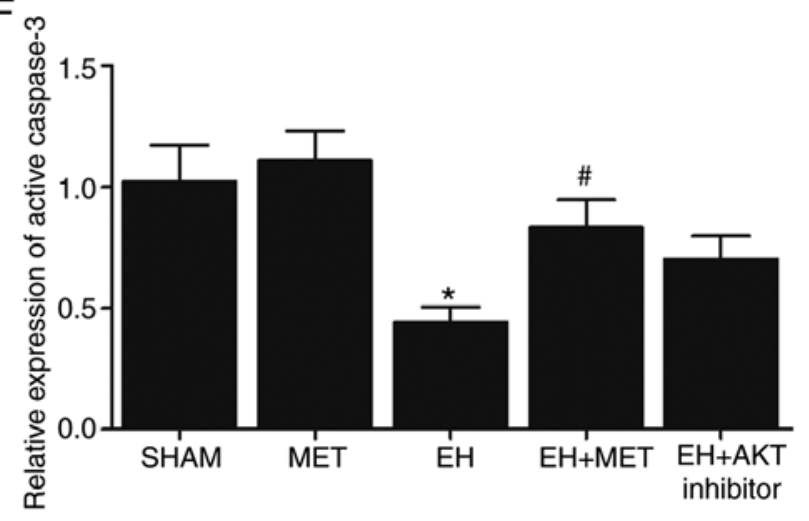

Figure 5. Expression levels of TGF- $\beta$, total AKT, p-AKT and active Caspase- 3 following Met treatment. (A) Western blots of TGF- $\beta$, total AKT, p-AKT, total Caspase-3 and active Caspase-3 in the different groups. (B) TGF- $\beta 1$, (C) total AKT, (D) p-AKT, (E) total Caspase-3 and (F) active Caspase-3 protein expression levels are shown. The protein levels of TGF- $\beta$ and p-AKT in the EH group were significantly higher compared with those in the sham group, while Met treatment in the EH group reduced these levels to a certain extent. By contrast, the protein level of active Caspase-3 was significantly reduced in the EH group compared with the sham group, while Met treatment in the EH group increased this protein level to a certain extent. Met treatment exerted no effect on the protein expression levels of total AKT and total Caspase- $3 .{ }^{*} \mathrm{P}<0.05$ vs. sham group; ${ }^{*} \mathrm{P}<0.05$ vs. EH group ( $\mathrm{N}=3$ ). Met, metformin; EH, endometrial hyperplasia; UCA1, urothelial cancer associated 1 ; miR-144, microRNA-144; TGF- $\beta 1$, transforming growth factor- $\beta 1$.
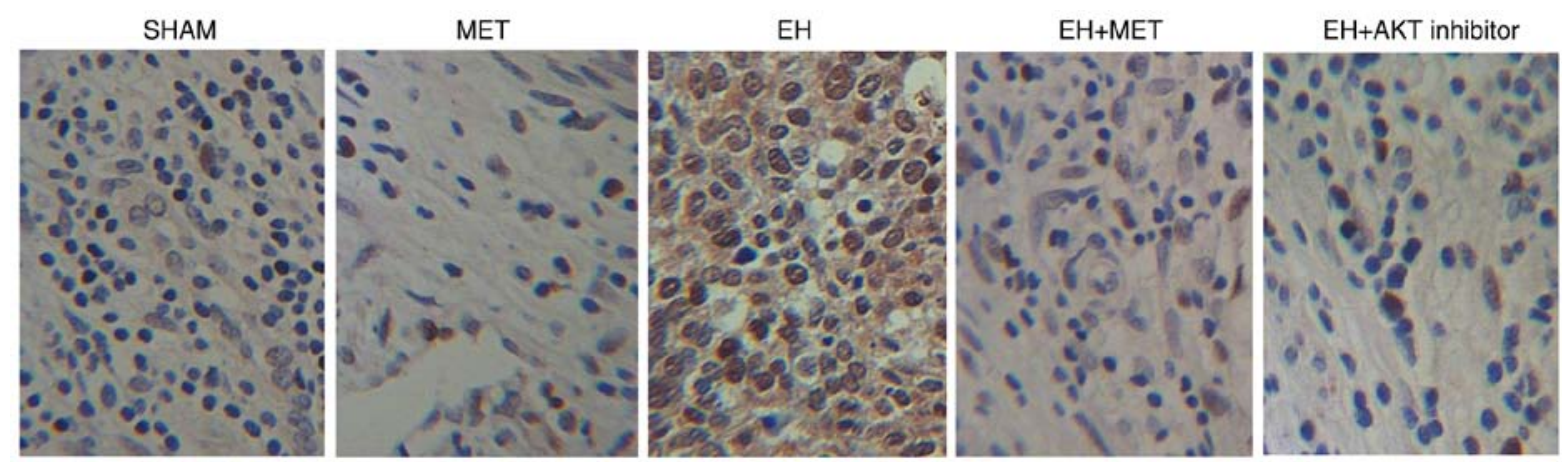

Figure 6. Immunohistochemical analysis was also conducted to compare the protein expression of TGF- $\beta$ among the sham, EH, Met and EH + Met groups. The results revealed that the protein level of TGF- $\beta$ in the EH group was evidently higher than that in the sham group, while the treatment with Met partially restored the normal protein expression of TGF- $\beta$ in the EH group (magnification, $x 400$ ). Met, metformin; EH, endometrial hyperplasia; TGF- $\beta$, transforming growth factor- $\beta$. 

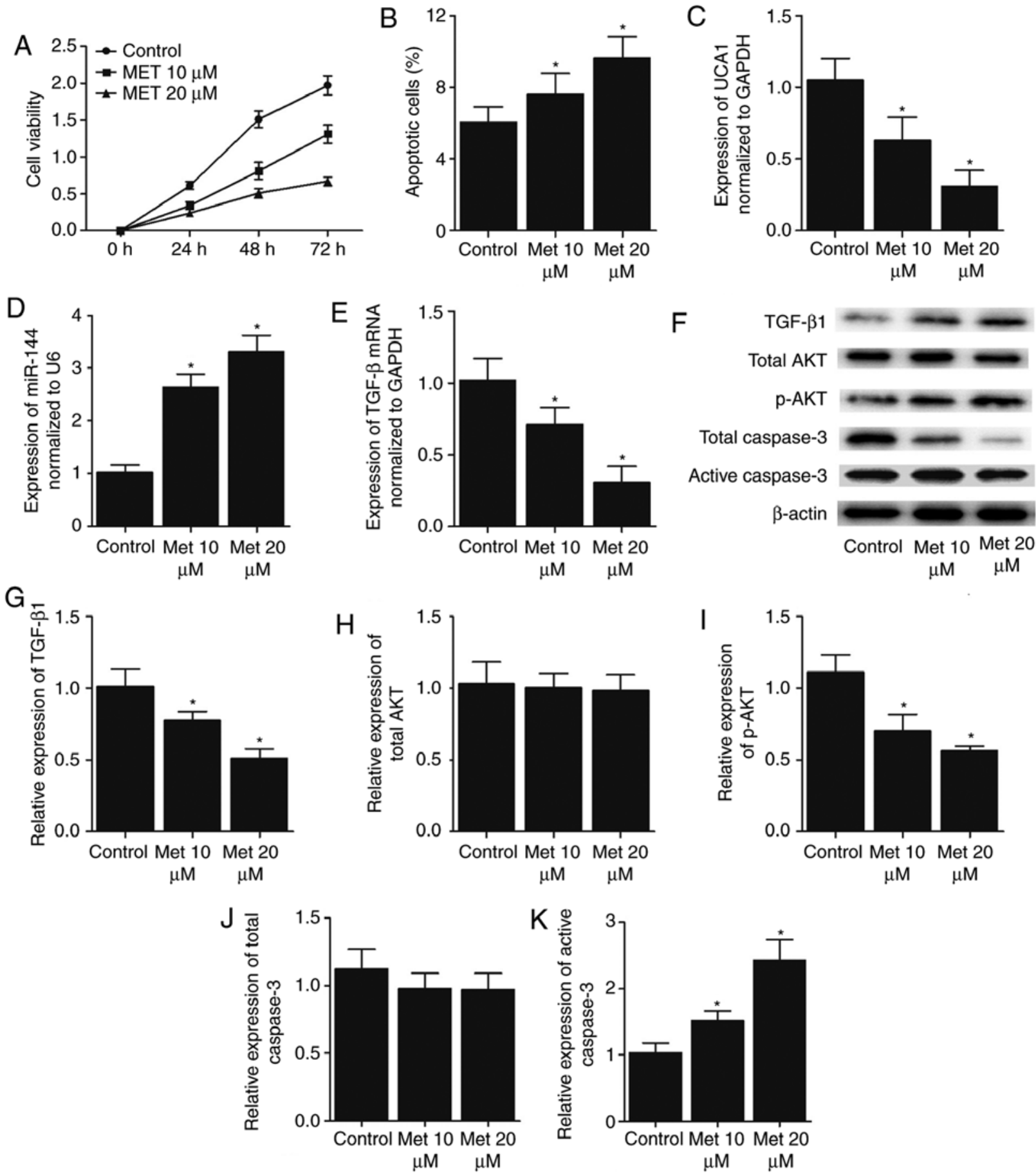

Figure 7. Met affected cell survival and the expression levels of key EH markers in AN3CA cells. (A) Viability was reduced and (B) apoptosis was increased dose-dependently in AN3CA cells following the administration of Met. (C) UCA1 mRNA, (D) miR-144 and (E) TGF- $\beta$ mRNA expression levels in AN3CA cells. Met treatment dose-dependently reduced the mRNA levels of UCA1 and TGF- $\beta$, and enhanced miR-144 expression. (F) Western blot analysis, and protein levels of (G) TGF- $\beta 1,(\mathrm{H})$ total AKT, (I) p-AKT, (J) total Caspase-3 and (K) active Caspase-3. Met treatment dose-dependently reduced the protein levels of TGF- $\beta$ and p-AKT, while increasing the protein expression of active Caspase-3. By contrast, Met treatment exerted no effect on the protein level of total AKT and total Caspase-3 in AN3CA cells. " $\mathrm{P}<0.05$ vs. control group ( $\mathrm{N}=3$ ). Met, metformin; UCA1, urothelial cancer associated 1; miR-144, microRNA-144; TGF- $\beta$, transforming growth factor- $\beta$.

treatment dose-dependently reduced the expression levels of UCA1, TGF- $\beta$ and $\mathrm{p}-\mathrm{AKT}$, while increasing the expression of miR-144 and active Caspase-3. However, Met treatment exerted no effect on the expression of total AKT and total Caspase-3.

As a major signaling pathway of TGF- $\beta 1$, the phosphatidylinositol 3-kinase (PI3K) signaling serves an essential role in a wide range of cellular processes (33). For instance, by phosphorylating and converting PIP2 to PIP3 on the cell membrane, PI3K facilitates the interaction between PIP3 and GTP-binding proteins, such as AKT, PKC, and Rac. As a major effector of PI3K, AKT is activated by a wide range of extracellular signals and growth factors to control numerous basic cellular processes, including cell 

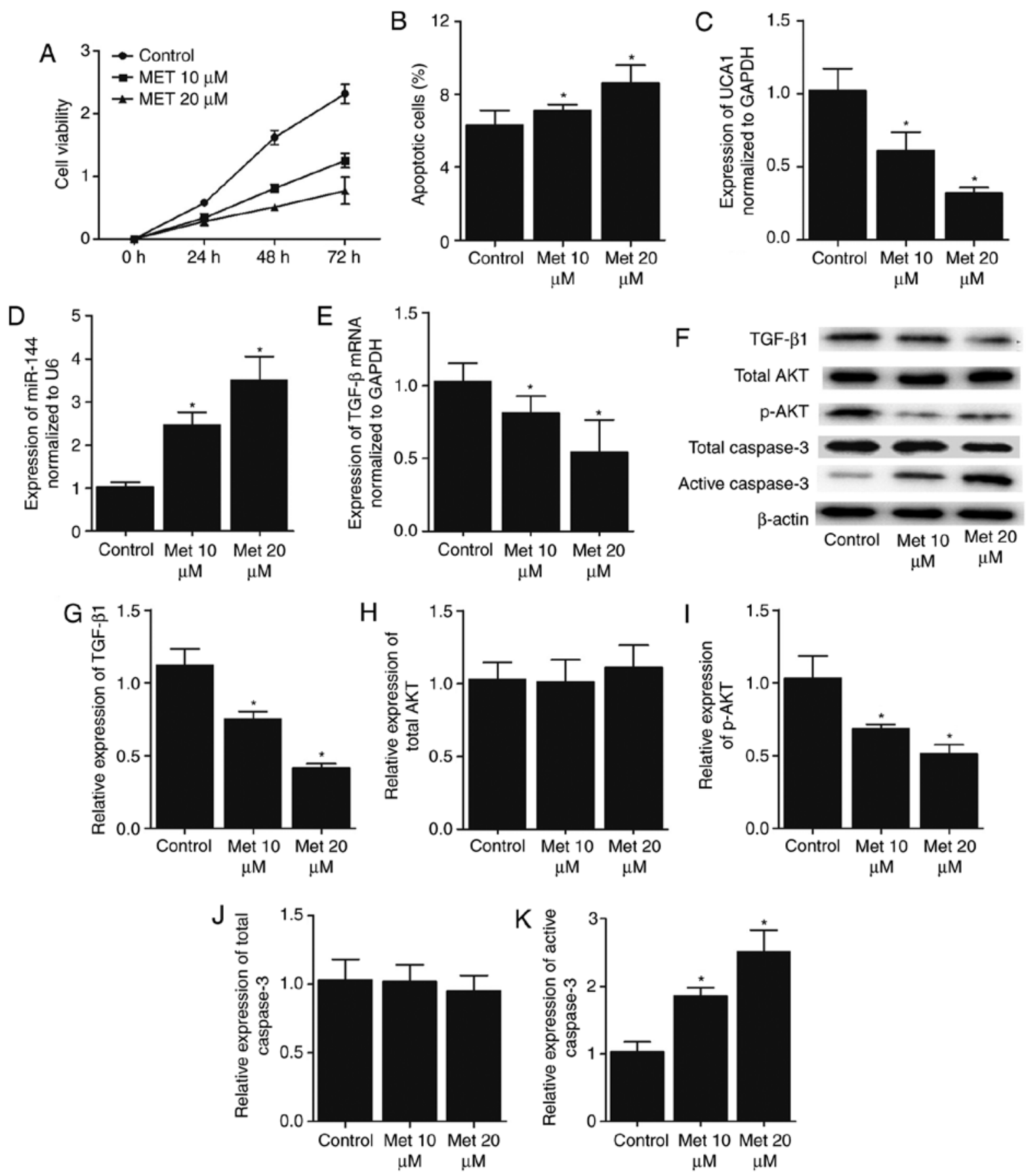

Figure 8. Met affected cell survival and the expression levels of key EH markers in Ishikawa cells. (A) Viability was reduced and (B) apoptosis was increased dose-dependently in Ishikawa cells following the administration of Met. (C) UCA1 mRNA, (D) miR-144 and (E) TGF- $\beta$ mRNA expression levels in Ishikawa cells. Met treatment in Ishikawa cells dose-dependently reduced the mRNA levels of UCA1 and TGF- $\beta$, and enhanced miR-144 expression. (F) Western blot analysis, and protein levels of (G) TGF- $\beta 1,(\mathrm{H})$ total AKT, (I) p-AKT, (J) total Caspase-3 and (K) active Caspase-3. Met treatment in Ishikawa cells dose-dependently decreased the protein expression levels of TGF- $\beta$ and p-AKT, while increasing the protein expression of active Caspase-3. However, Met treatment exerted no effect on the protein level of total AKT and total Caspase-3 in Ishikawa cells. ${ }^{*}<0.05$ vs. control group ( $\mathrm{N}=3$ ). Met, metformin; UCA1, urothelial cancer associated 1 ; miR-144, microRNA-144; TGF- $\beta$, transforming growth factor- $\beta$.

proliferation, apoptosis, division and survival (33). Other intracellular signaling pathways, including the extracellular signal-regulated kinase 1/2 pathway, have been implicated in carcinogenesis (34). Notably, the inactivation of the TGF- $\beta$ pathway has been reported to occur prior to the onset of EH. Thus, the identification of TGF- $\beta$ targets in the development of EH and EC may provide a novel way to prevent tumor escape from immune responses (35). Furthermore, if the level of TGF- $\beta$ receptor expression can be increased during the treatment of $\mathrm{EH}$, a novel therapeutic modality may be developed to restore impaired TGF- $\beta$ signaling in $\mathrm{EH}$ and EC (31). It has also been demonstrated that K-1 inactivated the Wnt/ $\beta$-catenin and Wnt7a/FZD6 signaling pathways in EH cells. K-1 can also reduce PI3K/AKT phosphorylation, thus promoting the apoptosis of primary EH cells (36). 
Nevertheless, there are limitations in the current study. Although the effect of Met in the prognosis and treatment of EH was demonstrated, only animal and cellular models were utilized. In addition, while treatment of the EH animal model with miR-144 was attempted, it was observed that the concentration in the target organ, the uterus, was not significantly elevated, as expected. To further confirm the study findings, further clinical data will be needed and corresponding clinical trials are necessary.

In conclusion, in the current study, tamoxifen was used to establish a mouse model of $\mathrm{EH}$, which exhibited increased levels of UCA1, TGF- $\beta$ and p-AKT, along with decreased levels of miR-144 and active Caspase-3. Notably, Met treatment partially restored the normal expression levels of UCA1, TGF- $\beta$, p-AKT, miR-144 and active Caspase- 3 in a dose-dependent manner. Furthermore, Met treatment inhibited cell proliferation and promoted cell apoptosis.

\section{Acknowledgements}

Not applicable.

\section{Funding}

No funding was received.

\section{Availability of data and materials}

The datasets used and/or analyzed during the current study are available from the corresponding author on reasonable request.

\section{Authors' contributions}

MG designed the current study. MG, JZ and WH collectted and analyzed the data. JZ collected the literature. WH and MG composed the manuscript.

\section{Ethics approval and consent to participate}

All experiments were performed according to the protocol approved by the Ethical Committee of Baoji Maternal and Child Health Hospital (Baoji, China).

\section{Patient consent for publication}

Not applicable.

\section{Competing interests}

The authors declare that they have no competing interests.

\section{References}

1. Horn LC, Schnurrbusch U, Bilek K, Hentschel B and Einenkel J: Risk of progression in complex and atypical endometrial hyperplasia: Clinicopathologic analysis in cases with and without progestogen treatment. Int J Gynecol Cancer 14: 348-353, 2004.

2. Ozdegirmenci O, Kayikcioglu F, Bozkurt U, Akgul MA and Haberal A: Comparison of the efficacy of three progestins in the treatment of simple endometrial hyperplasia without atypia. Gynecol Obstet Invest 72: 10-14, 2011.
3. Daud S, Jalil SS, Griffin M and Ewies AA: Endometrial hyperplasia-the dilemma of management remains: A retrospective observational study of 280 women. Eur J Obstet Gynecol Reprod Biol 159: 172-175, 2011

4. Nieman KM, Romero IL, Van Houten B and Lengyel E: Adipose tissue and adipocytes support tumorigenesis and metastasis. Biochim Biophys Acta 1831: 1533-1541, 2013.

5. Sheppard D: Transforming growth factor beta: A central modulator of pulmonary and airway inflammation and fibrosis. Proc Am Thorac Soc 3: 413-417, 2006.

6. ten Dijke P and Hill CS: New insights into TGF-beta-Smad signalling. Trends Biochem Sci 29: 265-273, 2004.

7. Bakin AV, Rinehart C, Tomlinson AK and Arteaga CL: p38 mitogen-activated protein kinase is required for TGFbeta-mediated fibroblastic transdifferentiation and cell migration. J Cell Sci 115: 3193-3206, 2002.

8. Gao Y, Li S and Li Q: Uterine epithelial cell proliferation and endometrial hyperplasia: Evidence from a mouse model. Mol Hum Reprod 20: 776-786, 2014.

9. Wilusz JE, Sunwoo H and Spector DL: Long noncoding RNAs: Functional surprises from the RNA world. Genes Dev 23: 1494-1504, 2009.

10. Mercer TR, Dinger ME and Mattick JS: Long non-coding RNAs: Insights into functions. Nat Rev Genet 10: 155-159, 2009.

11. Eulalio A, Huntzinger E and Izaurralde E: Getting to the root of miRNA-mediated gene silencing. Cell 132: 9-14, 2008.

12. Iorio MV, Ferracin M, Liu CG, Veronese A, Spizzo R, Sabbioni S, Magri E, Pedriali M, Fabbri M, Campiglio M, et al: MicroRNA gene expression deregulation in human breast cancer. Cancer Res 65: 7065-7070, 2005.

13. Zhang ZS, Wang J, Zhu BQ and Ge L: Long noncoding RNA UCA1 promotes multiple myeloma cell growth by targeting TGF- $\beta$. Eur Rev Med Pharmacol Sci 22: 1374-1379, 2018.

14. Li D, Li H, Yang Y and Kang L: Long noncoding RNA urothelial carcinoma-associated 1 promotes the proliferation and metastasis of human lung tumor cells by regulating MicroRNA-144. Oncol Res 26: 537-546, 2018.

15. LiT, SunX and Jiang X: UCA1 involvedinthe metformin-regulated bladder cancer cell proliferation and glycolysis. Tumour Biol 39: $1010428317710823,2017$.

16. Livak KJ and Schmittgen TD: Analysis of relative gene expression data using real-time quantitative PCR and the 2(-Delta Delta C(T)) method. Methods 25: 402-408, 2001.

17. Matias-Guiu X, Catasus L, Bussaglia E, Lagarda H, Garcia A, Pons C, Muñoz J, Argüelles R, Machin P and Prat J: Molecular pathology of endometrial hyperplasia and carcinoma. Hum Pathol 32: 569-577, 2001.

18. Pernicova I and Korbonits M: Metformin-mode of action and clinical implications for diabetes and cancer. Nat Rev Endocrinol 10: 143-156, 2014.

19. Nestler JE: Metformin for the treatment of the polycystic ovary syndrome. N Engl J Med 358: 47-54, 2008.

20. Shao R, Li X, Feng Y, Lin JF and Billig H: Direct effects of metformin in the endometrium: A hypothetical mechanism for the treatment of women with PCOS and endometrial carcinoma. J Exp Clin Cancer Res 33: 41, 2014.

21. Shen ZQ, Zhu HT and Lin JF: Reverse of progestin-resistant atypical endometrial hyperplasia by metformin and oral contraceptives. Obstet Gynecol 112: 465-467, 2008.

22. Xie Y, Wang YL, Yu L, Hu Q, Ji L, Zhang Y and Liao QP: Metformin promotes progesterone receptor expression via inhibition of mammalian target of rapamycin (mTOR) in endometrial cancer cells. J Steroid Biochem Mol Biol 126: 113-120, 2011.

23. Sharifzadeh F, Aminimoghaddam S, Kashanian M, Fazaeli M and Sheikhansari N: A comparison between the effects of metformin and megestrol on simple endometrial hyperplasia. Gynecol Endocrinol 33: 152-155, 2017.

24. Wang T, Zhang J, Hu M, Zhang Y, Cui P, Li X, Li J, Vestin E, Brännström M, Shao LR and Billig H: Differential expression patterns of glycolytic enzymes and mitochondria-dependent apoptosis in PCOS patients with endometrial hyperplasia, an early hallmark of endometrial cancer, in vivo and the impact of metformin in vitro. Int J Biol Sci 15: 714-725, 2019.

25. Shan W, Wang C, Zhang Z, Gu C, Ning C, Luo X, Zhou Q and Chen X: Conservative therapy with metformin plus megestrol acetate for endometrial atypical hyperplasia. J Gynecol Oncol 25: 214-220, 2014

26. Sivalingam VN, Kitson S, McVey R, Roberts C, Pemberton P Gilmour K, Ali S, Renehan AG, Kitchener HC and Crosbie EJ: Measuring the biological effect of presurgical metformin treatment in endometrial cancer. Br J Cancer 114: 281-289, 2016. 
27. Ben Sahra I, Tanti JF and Bost F: The combination of metformin and 2-deoxyglucose inhibits autophagy and induces AMPK-dependent apoptosis in prostate cancer cells. Autophagy 6: 670-671, 2010.

28. Jiralerspong S, Palla SL, Giordano SH, Meric-Bernstam F Liedtke C, Barnett CM, Hsu L, Hung MC, Hortobagyi GN and Gonzalez-Angulo AM: Metformin and pathologic complete responses to neoadjuvant chemotherapy in diabetic patients with breast cancer. J Clin Oncol 27: 3297-3302, 2009.

29. Rattan R, Graham RP, Maguire JL, Giri S and Shridhar V: Metformin suppresses ovarian cancer growth and metastasis with enhancement of cisplatin cytotoxicity in vivo. Neoplasia 13: 483-491, 2011

30. Li X, Guo YR, Lin JF, Feng Y, Billig H and Shao R: Combination of diane-35 and metformin to treat early endometrial carcinoma in PCOS women with insulin resistance. J Cancer 5: 173-181, 2014.

31. Lee TY, Martinez-Outschoorn UE, Schilder RJ, Kim CH, Richard SD, Rosenblum NG and Johnson JM: Metformin as a therapeutic target in endometrial cancers. Front Oncol 8: 341, 2018
32. Tabrizi AD, Melli MS, Foroughi M, Ghojazadeh M and Bidadi S: Antiproliferative effect of metformin on the endometrium-a clinical trial. Asian Pac J Cancer Prev 15: 10067-10070, 2014

33. Cantrell DA: Phosphoinositide 3-kinase signalling pathways. J Cell Sci 114: 1439-1445, 2001.

34. Santarpia L, Lippman SM and El-Naggar AK: Targeting the MAPK-RAS-RAF signaling pathway in cancer therapy. Expert Opin Ther Targets 16: 103-119, 2012.

35. Parekh TV, Gama P, Wen X, Demopoulos R, Munger JS, Carcangiu ML, Reiss M and Gold LI: Transforming growth factor beta signaling is disabled early in human endometrial carcinogenesis concomitant with loss of growth inhibition. Cancer Res 62: 2778-2790, 2002.

36. Chandra V, Fatima I, Manohar M, Popli P, Sirohi VK, Hussain MK, Hajela K, Sankhwar P and Dwivedi A: Inhibitory effect of 2-(piper idinoethoxyphenyl)-3-(4-hydroxyphenyl)-2H-benzo(b)pyran (K-1) on human primary endometrial hyperplasial cells mediated via combined suppression of $\mathrm{Wnt} / \beta$-catenin signaling and PI3K/Akt survival pathway. Cell Death Dis 5: e1380, 2014. 